\title{
Morphology and contact angle studies of poly(styrene-co-acrylonitrile) modified epoxy resin blends and their glass fibre reinforced composites
}

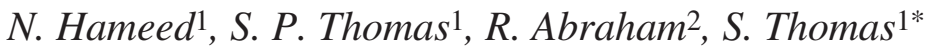 \\ ${ }^{1}$ School of Chemical Sciences, Mahatma Gandhi University, P. D. Hills, Kottayam, 686 560, India \\ ${ }^{2}$ Department of Physics, St. Dominic's College, Kanjirappilly, Kottayam, Kerala, India
}

Received 1 April 2007; accepted in revised form 4 May 2007

\begin{abstract}
In this study, the surface characteristics of blends and composites of epoxy resin were investigated. Poly(styreneco-acylonitrile) (SAN) was used to modify diglycidyl ether of bisphenol-A (DGEBA) type epoxy resin cured with diamino diphenyl sulfone (DDS) and the modified epoxy resin was used as the matrix for fibre reinforced composites (FRP's). E-glass fibre was used as the fibre reinforcement. The scanning electron micrographs of the fractured surfaces of the blends and composites were analyzed. Morphological analysis revealed different morphologies such as dispersed, cocontinuous and phase-inverted structures for the blends. Contact angle studies were carried out using water and methylene iodide at room temperature. The solid surface energy was calculated using harmonic mean equations. Blending of epoxy resin increases its contact angle. The surface free energy, work of adhesion, interfacial free energy, spreading coefficient and Girifalco-Good's interaction parameter were changed significantly in the case of blends and composites. The incorporation of thermoplastic and glass fibre reduces the wetting and hydrophilicity of epoxy resin.
\end{abstract}

Keywords: thermosetting resins, polymer composites, morphology, contact angle, wettability

\section{Introduction}

Among the thermosetting polymers, epoxy resins are the most widely used for high performance applications such as, matrices for fibre reinforced composites, coatings, structural adhesives and other engineering applications [1]. Many studies have been made to improve their toughness and crack resistance. In recent years, high performance thermoplastics have been extensively used to toughen thermosetting resins because of their high modulus and glass transition temperatures [2-4]. Morphology of the resulting polymer blends depends on the selection of the thermoplastic polymer, the epoxy precursors, hardener and on the curing cycle parameters [5-7]. The phase separation upon crosslinking is due to the increase in molecu- lar weight of epoxy resin. This reaction induced phase separation (RIPS) leads to different morphologies. Dispersed, cocontinuous or phaseinverted structures can be obtained. Thermosets have historically been the principal matrix material for fibre reinforced composites for many applications [8-10].

A great deal of research interest has been made on the study of the wetting phenomena of polymeric systems [11-13]. An appropriate experimental technique for quantifying the surface properties of solids is the measurement of contact angles of liquids on solid surfaces. The term wettability is used to describe the extent to which a liquid spreads on a solid surface. The interfacial properties between a liquid and a polymer component are characterized

*Corresponding author, e-mail: sabut@ sancharnet.in

(C) BME-PT and GTE 
by the surface energies of each phase and the contact angle between them. The contact angle method is relatively simple, very useful and highly sensitive to investigate the interfacial phenomena. The contact angle is an important parameter in surface science. It is the angle between the surface of the wetted solid and a line tangent to the curved surface of the drop at the point of three-phase contact.

In this paper, systematical experimental studies on the morphological and wetting behaviour of epoxy resin (DGEBA) modified with SAN (Styrene Acrylonitrile) and then reinforced with glass fibres were made. The phase separation in blends and arrangement of fibres in composites were investigated. The hydrophilic/hydrophobic nature of the specimens was well established. The study is aimed to reduce the hydrophilic nature of epoxy resin by thermoplastic modification. The study is also directed to the effect of thermoplastic/fibre content on the surface properties of blends and composites.

\section{Experimental}

\subsection{Materials used}

Commercially available diglycidyl ether of bisphenol-A (DGEBA) epoxy resin (L-12, Atul Ltd., India) with an epoxide equivalent of 180-200 was used. The curing agent used was 4,4'-diaminodiphenyl sulfone (DDS, Atul Ltd., India). The thermoplastic modifier used was poly(styrene-coacrylonitriole) (SAN-A, Bayer, Germany) with $25 \%$ of acrylonitrile (AN) content. The reinforcement (chopped E-glass fibre mat) was supplied by Ceat Ltd., India. The density of glass fibre is

Table 1. Composition of E-glass fibre

\begin{tabular}{|l|c|c|c|c|c|c|}
\hline $\begin{array}{c}\text { Glass fibre } \\
\text { type }\end{array}$ & $\mathrm{SiO}_{2}$ & $\mathrm{Al}_{\mathbf{2}} \mathrm{O}_{\mathbf{3}}$ & $\mathbf{C a O}$ & $\mathbf{M g O}$ & $\mathbf{B}_{2} \mathbf{O}_{3}$ & $\mathrm{Na}_{2} \mathbf{O}$ \\
\hline E-glass & 54.5 & 14.5 & 17 & 4.5 & 8.5 & 0.5 \\
\hline
\end{tabular}

$2.51 \mathrm{~g} / \mathrm{cm}^{3}$. The chemical structures of epoxy resin and DDS are given in Figure 1. The composition of E-glass fibre is given in Table 1.

\subsection{Blend preparation}

Melt-mixing technique was adopted for the preparation of blends. SAN was first dissolved in epoxy resin at $180^{\circ} \mathrm{C}$ with constant stirring in a magnetic stirrer. After getting a homogeneous solution, stoichiometric amount of DDS was added and dissolved completely without changing the temperature. The resulting solution was poured in to an open mould. The blend was cured at $180^{\circ} \mathrm{C}$ for 3 hours and then post cured at $200^{\circ} \mathrm{C}$ for 2 hours in an oven. After curing, blends were allowed to cool slowly to room temperature. Blends with 5, 10, 15 and $20 \mathrm{phr}$ SAN were prepared.

\subsection{Composite preparation}

Fibre reinforced composites were fabricated using the compression moulding technique. Glass fibre mat was cut to size and heated in an oven at $150^{\circ} \mathrm{C}$ to make it moisture free before processing. $10 \mathrm{phr}$ blend was used as the matrix for composites. The SAN modified epoxy resin and hardener mixture, before curing, was applied to the pre-weighed glass fibre sheets. Eight layers were added successively in order to get $3 \mathrm{~mm}$ thickness for the composites. The laminates were compressed in a mould. It is then cured at $180^{\circ} \mathrm{C}$ for 3 hours and then post cured at $200^{\circ} \mathrm{C}$ for 2 hours. The laminates were allowed to cool slowly to room temperature. Four different compositions were prepared, where the resin-fibre volume ratio are 70:30, 60:40, 50:50 and 40:60 respectively. The composites were also prepared using neat epoxy as the matrix for comparison. Blends were designated as ES5, ES10, ES15 and ES20, where E and S correspond to epoxy resin and<smiles>CC(C)(C)Oc1ccc(OCC(O)CC(C)(CC(C)(C)c2ccc(OCC3CO3)cc2)Oc2ccc(C(C)(C)c3ccc(C(C)(C)C4CO4)cc3)cc2)cc1</smiles>

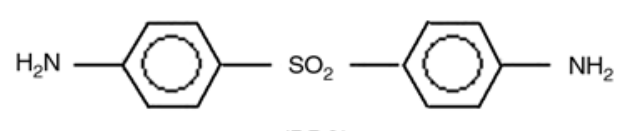

(DDS)

Figure 1. Chemical structures of epoxy resin and DDS 
SAN respectively and the numbers $5,10,15$ and 20 represent the wt\% of SAN (in phr). The composites were designated as EG30, EG40, EG50, EG60, ESG30, ESG40, ESG50 and ESG60 where the numbers represent the fibre volume from 30 to $60 \%$ and $\mathrm{G}$ represents the glass fibre.

\section{Characterization}

\subsection{Scanning electron microscopy}

The morphology of the blends and composites was examined using scanning electron microscopy (SEM). The SEM micrographs of failed specimens were analyzed with a Zeiss FESEM Supra 25 scanning electron microscope.

\subsection{Contact angle}

Contact angle measurements of the blends and composites were conducted in a FTA 100 series (First Ten Angstroms, Portsmouth, Virginia 23704, USA). Water (distilled many times) and methylene iodide (Kemphasol, Bombay) were used for the analyses of samples. Measurements were carried out on samples of dimension $6 \times 2 \times 0.3 \mathrm{~cm}^{3}$ at room temperature in closed chambers. The volume of the sessile drop was maintained as $5 \mu \mathrm{l}$ in all cases using a microsyringe. For accuracy, measurements were repeated 5-10 times on different pieces of the same sample.

\section{Theory and calculations}

When a liquid drop is brought onto the surface of a solid, the contact of liquid/solid reaches an equilibrium condition and we say the liquid drop is in a static state. Whether it will wet the surface or not depends on the relative magnitudes of the molecular forces that exist within the liquid (cohesive) and between the liquid and the solid (adhesive). The angle with which the liquid subtends the solid is known as the contact angle $(\theta)$ as shown in Figure 2. Such a contact angle is used to characterize the wettability of a liquid on a solid surface. Because the contact angle ranges from 0 to $180^{\circ}$, there are two extreme cases. If the contact angle is equal to $0^{\circ}$, i. e., a liquid film is formed on a solid surface, then we can say that a perfect wetting occurs. The other case is that the contact angle is equal to $180^{\circ}$, i. e., a perfect liquid sphere is set on the solid surface. In this case, the contact angle is

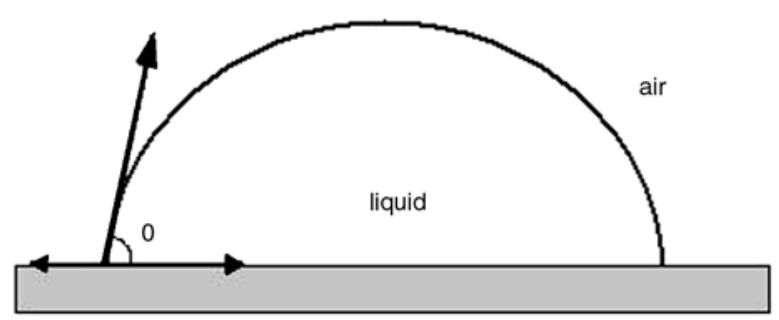

Figure 2. Sessile drop spread wetting

related to the characteristic surface energies of different interfaces among the liquid used and solid surfaces.

It is well established from the literature that contact angle measurements can be used in the calculation of surface tensions [14-16]. In the case of pure liquids and smooth, homogeneous, rigid, and insoluble solid surfaces, the contact angle is a thermodynamic parameter, which can be used to calculate the solid interfacial tension by different techniques $[16,17]$. These techniques were inspired by the idea of using the Equation (1) first derived by Thomas Young in 1805 which is given by [13]:

$\cos \theta=\frac{\gamma_{s}-\gamma_{s l}}{\gamma_{l}}$

This equation is a thermodynamic equilibrium condition for an ideal solid-liquid-fluid capillary system. The contact angle $(\theta)$ is uniquely determined by the three surface energies namely, the surface energy of the solid $\left(\gamma_{s}\right)$, surface energy of the liquid $\left(\gamma_{l}\right)$ and the interfacial free energy between the solid and the liquid $\left(\gamma_{s l}\right)$. The condition for the derivation of Young's equation is the requirement of a homogeneous, inert, non-porous and non-deformable solid surface.

In Equation (1), the values of $\gamma_{s}$ and $\gamma_{l}$ cannot be determined directly. An approximate measure of surface free energy of the solid $\left(\gamma_{s}\right)$ can be taken as the critical surface tension $\left(\gamma_{c}\right)$ at which $\cos \theta=1$ [18]. The critical surface tension can be obtained by the extrapolation of the plot of $\cos \theta$ against the surface tension for a homologous series of liquids. However, the precise value of $\gamma_{s}$ depends on the particular series of liquids used to determine it. Considering the solid dispersion forces, Fowkes [19] presented a more appropriate method using a geometric mean equation. Modification of Fowkes equation was later made by Owens and Wendt [20] and Kaelble [21] assuming the polar attraction forces. Wu [22] used a harmonic equation to obtain 
the value of $\gamma_{s}$, which combines both the polar and dispersion forces. Wu's approach has been satisfactorily verified by several other authors [23, 24]. To verify Wu's approach, two liquids of dissimilar polarity are selected. For obtaining the $\gamma_{s}$ of polymers, water and methylene iodide have been reported as the useful pair of liquids [25]. The harmonic mean equations for water and methylene iodide are given as Equations (2) and (3):

$$
\begin{aligned}
& \left(1+\cos \theta_{w}\right) \gamma_{w}=4\left[\frac{\gamma_{w}^{d} \gamma_{s}^{d}}{\gamma_{w}^{d}+\gamma_{s}^{d}}+\frac{\gamma_{w}^{p} \gamma_{s}^{p}}{\gamma_{w}^{p}+\gamma_{s}^{p}}\right] \\
& \left(1+\cos \theta_{m}\right) \gamma_{m}=4\left[\frac{\gamma_{m}^{d} \gamma_{s}^{d}}{\gamma_{m}^{d}+\gamma_{s}^{d}}+\frac{\gamma_{m}^{p} \gamma_{s}^{p}}{\gamma_{m}^{p}+\gamma_{s}^{p}}\right]
\end{aligned}
$$

where the superscripts $d$ and $p$ stands for the contribution due to dispersion and polar forces respectively. Data for water and methylene iodide, taken from the literature [20] is given in the Table 2.

$\gamma_{s}^{d}$ and $\gamma_{s}^{p}$ for different samples of epoxy/SAN blends, epoxy/glass fibre composites and epoxy/ SAN/glass fibre composites were determined by solving Equations (2) and (3) with the help of a C program.

According to Owens-Wendt theory, the total free surface energy $\left(\gamma_{s}\right)$ is the sum of its dispersive $\left(\gamma_{s}^{d}\right)$ and polar $\left(\gamma_{s}^{p}\right)$ components (4):

$\gamma_{s}=\gamma_{s}^{d}+\gamma_{s}^{p}$

The work of adhesion $\left(W_{A}\right)$ can be calculated using the Equation (5):

$W_{A}=(1+\cos \theta) \gamma_{l}$

The interfacial free energy can be calculated using the Dupre's equation [26] (6):

$\gamma_{s l}=\gamma_{s}+\gamma_{l}-W_{A}$

The spreading coefficient $\left(S_{c}\right)$ [26] and GirifalcoGood's interaction parameter $(\phi)$ between the polymer and the liquid were calculated the using the Equations (7) and (8):

Table 2. The dispersive $\left(\gamma_{l}^{d}\right)$ and polar $\left(\gamma_{l}^{p}\right)$ components and surface energy $\left(\gamma_{l}\right)$ for selected liquids

\begin{tabular}{|l|c|c|c|}
\hline \multicolumn{1}{|c|}{ Liquid } & $\gamma_{l}\left[\mathbf{m J} / \mathbf{m}^{2}\right]$ & $\gamma_{l}^{d}\left[\mathbf{m J} / \mathbf{m}^{2}\right]$ & $\gamma_{l}^{p}\left[\mathbf{m J} / \mathbf{m}^{2}\right]$ \\
\hline Water & 72.8 & 21.8 & 51.0 \\
\hline Methylene iodide & 50.8 & 49.5 & 1.3 \\
\hline
\end{tabular}

$$
\begin{aligned}
& S_{c}=\gamma_{s}-\gamma_{s l}-\gamma_{l} \\
& \phi=\frac{\gamma_{l}(1+\cos \theta)}{2\left(\gamma_{l} \gamma_{s}\right)^{\frac{1}{2}}}
\end{aligned}
$$

\section{Results and discussion}

\subsection{Morphological analysis}

Morphological analysis of the blend was performed using scanning electron microscopy. The SEM micrographs of fractured surfaces of epoxy/SAN blends are given in the Figure 3. The micrographs confirm the two-phase morphology of the blends. The heterogeneous morphology of the blends is due to the reaction induced phase separation (RIPS). Initially the system was miscible due to the low molecular weight of the epoxy prepolymer but during curing, molecular weight increases and the contribution to the entropy and free energy of mixing lessened resulting in two-phase morphology. Different morphologies such as dispersed, cocontinuous and phase inverted were developed depending on the composition. $5 \mathrm{phr}$ and $10 \mathrm{phr}$ blends show dispersed morphology in which SAN particles are uniformly dispersed in the continuous epoxy phase. The number of domains increased with composi-
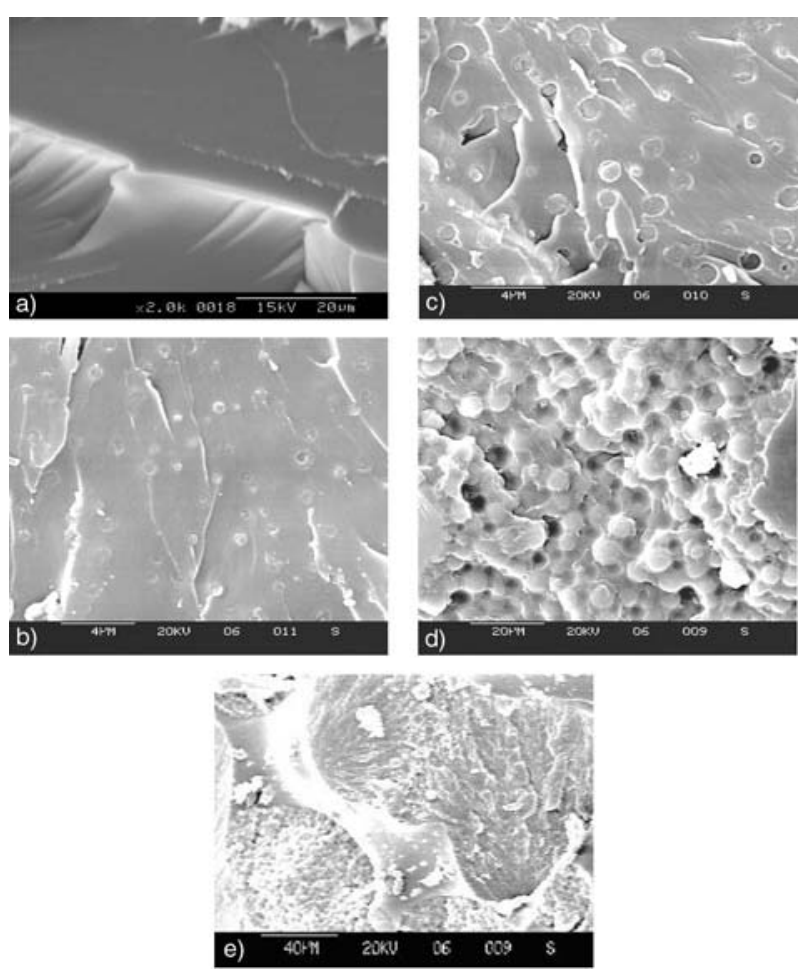

Figure 3. Scanning electron micrographs of different epoxy/SAN blends. a) neat epoxy, b) $5 \mathrm{phr}$, c) $10 \mathrm{phr}, \mathrm{d}) 15 \mathrm{phr}$, e) $20 \mathrm{phr}$ 
tion and the dispersed domains has uniform particle size distribution. The number average diameter $\left(\bar{D}_{n}\right)$, weight average diameter $\left(\bar{D}_{w}\right)$ and poly dispersity index $(P D I)$ of the $5 \mathrm{phr}$ and $10 \mathrm{phr}$ blends were calculated using the Equations (9), (10) and (11):

Number average diameter, $\bar{D}_{n}=\frac{\sum n_{i} d_{i}}{\sum n_{i}}$
Weight average diameter, $\bar{D}_{w}=\frac{\sum n_{i} d_{i}^{2}}{\sum n_{i} d_{i}}$

Polydispersity index, $P D I=\frac{\bar{D}_{w}}{\bar{D}_{n}}$

where $n_{i}$ is the number of domains having diameter $d_{i}$. The interparticle distance and interfacial area per unit volume were calculated using the Equations (12) and (13) [27]:

Interparticle distance $=d_{T P}\left[\left(\frac{\pi}{6 \phi_{T P}}\right)^{\frac{1}{2}}-1\right]$

Interfacial area per unit volumene $=\frac{3 \phi_{T P}}{r}$

$d_{T P}$ is the number average diameter of the domains, $r$ is the number average radius of the domains and $\phi_{T P}$ is the volume fraction of the dispersed phase. These parameters are given in Table 3. It can be seen that the domain diameter was increased with increase in SAN content while poly dispersity index remains constant indicating the uniform particle size distribution. The interparticle distance decreased whereas the interfacial area per unit volume increased on increasing the SAN content in the blends. In the case of $15 \mathrm{phr}$ blends the thermoplastic particles found to coagulate and results in cocontinuous morphology. When the SAN content is more than $15 \mathrm{phr}$, blends exhibited a phaseinverted morphology, which consisted of epoxy domains in thermoplastic continuous phase. This may be due to the viscosity difference between

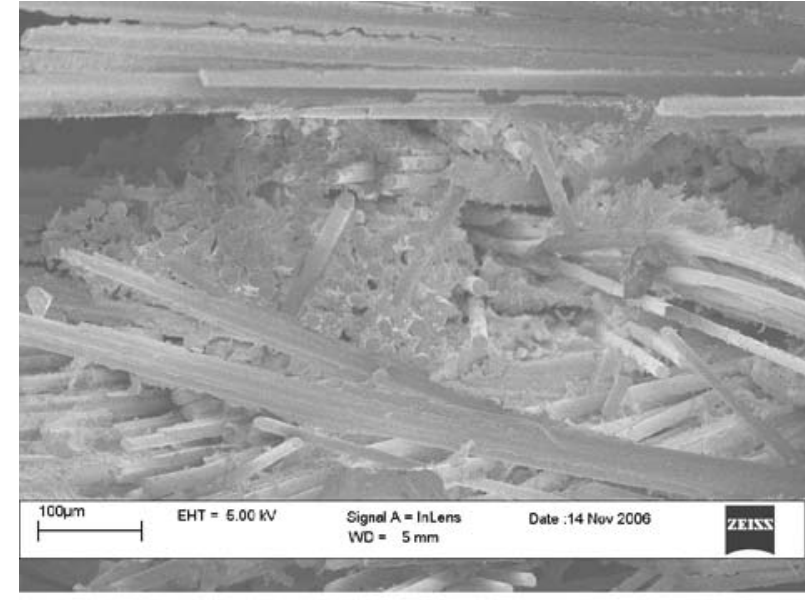

a)

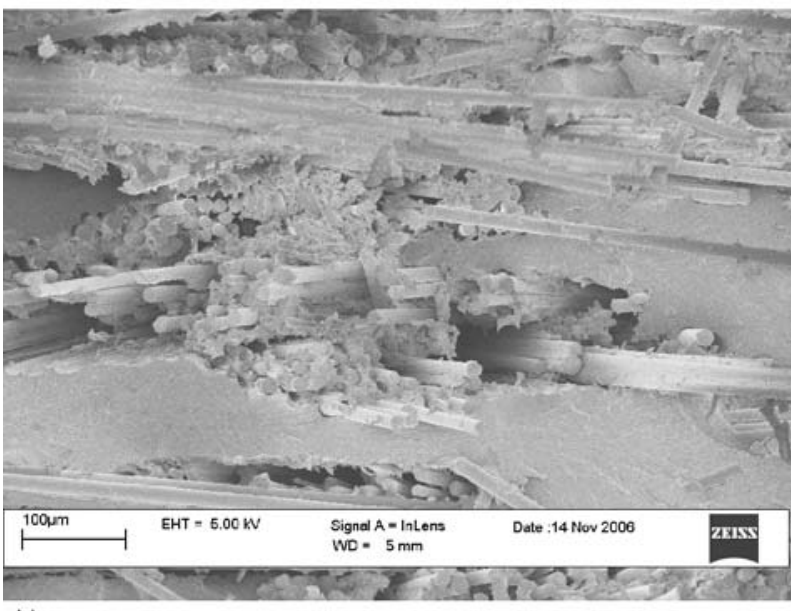

b)

Figure 4. Scanning electron micrographs of failed surfaces of epoxy/SAN/glass fibre composites.

a) EG, b) ESG

thermoset and thermoplastic [28]. The phase separation in thermoplastic modified epoxy resin occurs via. spinodal decomposition and is determined by the two competitive processes i. e., phase separation and crosslinking reaction [29]. The SEM of fractured surface, given in Figure 3, revealed that the surfaces of blends were rough and rigid but the surface of unmodified epoxy resin was smooth, indicating the characteristics of a brittle material. It is to be noted that the surface of the blend becomes more and more rough as the concentration of SAN increases. The roughness of the surface has a significant contribution to the surface properties of blends. The SEM pictures of epoxy/glass fibre composites with different fibre volume percentage

Table 3. The number average diameter, weight average diameter, poly dispersity index, interparticle distance and interfacial area per unit volume of epoxy/SAN blends

\begin{tabular}{|c|c|c|c|c|c|}
\hline SAN content $[\mathbf{p h r}]$ & $\mathbf{D}_{\mathbf{n}}[\boldsymbol{\mu m}]$ & $\mathbf{D}_{\mathbf{w}}[\boldsymbol{\mu m}]$ & $\mathbf{P D I}$ & Interparticle distance $[\boldsymbol{\mu m}]$ & ${\mathbf{I n t e r f a c i a l ~ a r e a ~ p e r ~ u n i t ~ v o l u m e ~}\left[\boldsymbol{\mu} \mathbf{m}^{-\mathbf{1}}\right]}$ \\
\hline 5 & 0.65 & 0.68 & 1.04 & 0.79 & 0.48 \\
\hline 10 & 0.97 & 1.01 & 1.05 & 0.66 & 0.69 \\
\hline
\end{tabular}


are shown in Figure 4. Here also the surface becomes rougher by the incorporation of fibres.

\subsection{Contact angle measurements}

The variation of contact angle against blend composition is given in the Figure 5. It can be observed that the blends possess higher contact angle compared to neat epoxy resin. The increase of contact angle of water and methylene iodide is prominent up to $20 \mathrm{phr}$ blends. The less affinity of the blends indicates the reduction in the hydrophilic nature of the blends due to the addition of thermoplastic.

Figure 6 represents the variation of contact angle with increase in volume percentage of glass fibre of neat epoxy/glass fibre composites (EGs) (Figure 6a) and epoxy/SAN/glass fibre composites (ESGs) (Figure 6b). In all cases the contact angle is high when compared to neat cured epoxy resin. In case of EGs, $\theta$ value increases with increase in fibre loading whereas ESGs shows a decline in the $\theta$ value after 50 vol\% fibre loading. This may be due to the presence of excess of non-polar groups on the surface of the blends by the addition of SAN. The increase in contact angle value can also be compared with the increase in surface roughness of the polymer surface [30]. It has been shown that the contact angle increases with increase in the roughness of the surface. The roughness of polymer surface was observed with SEM, (Figure 3 and Figure 4). The roughness of the sample surface increases by the addition of SAN thermoplastic in to the epoxy matrix. In the case of composites also, incorporation of glass fibres increases the surface roughness.

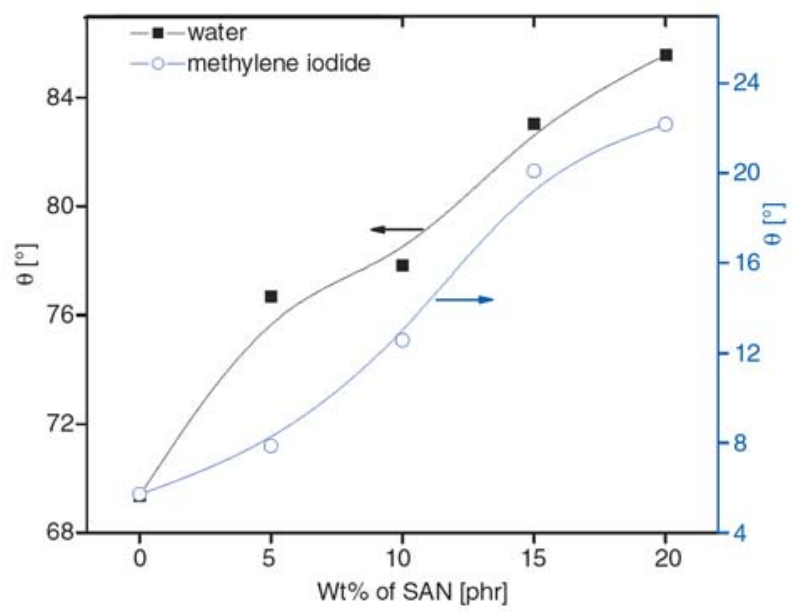

Figure 5. Contact angle against the SAN concentration for different epoxy/SAN blends
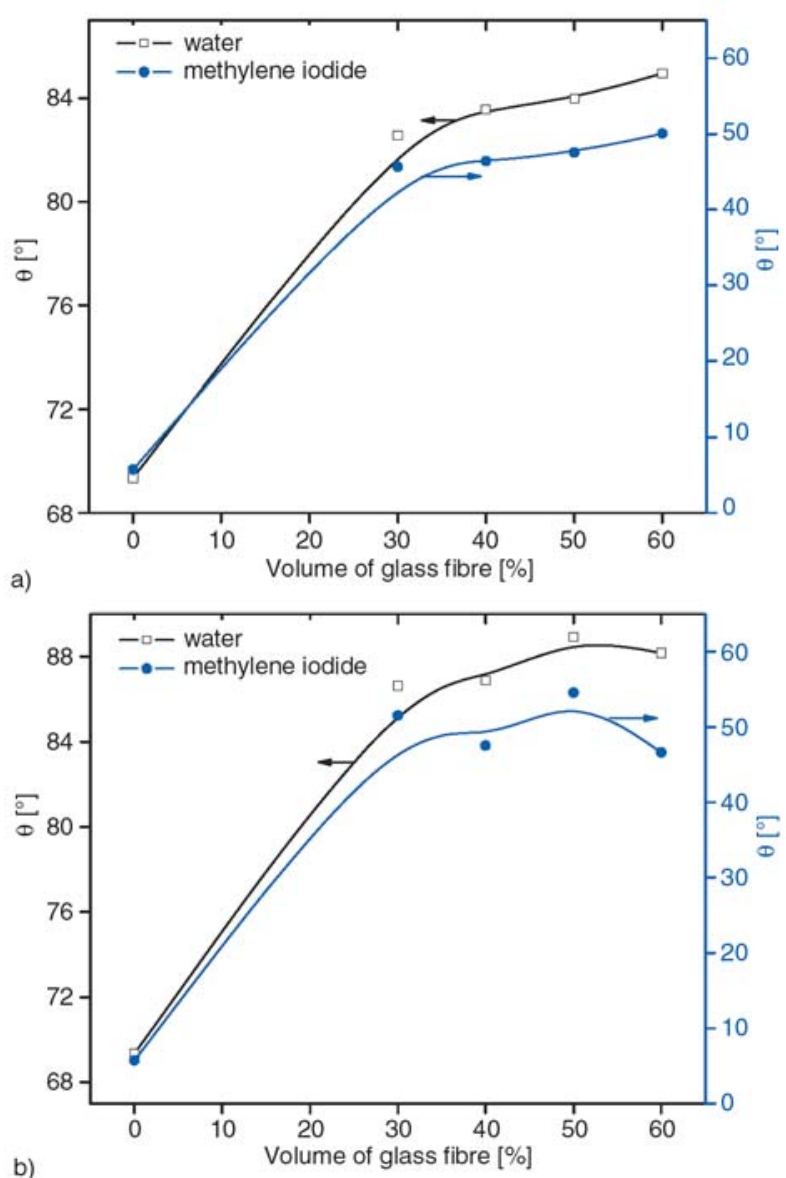

Figure 6 a) Contact angle against glass fibre concentration for epoxy/glass fibre composites (EGs), b) contact angle against glass fibre concentration for epoxy/SAN/glass fibre composites (ESGs)

Figures $7 \mathrm{a}$ and $7 \mathrm{~b}$ shows the typical contact angle data (water as the liquid) at various time intervals for the epoxy/SAN blends and epoxy/glass fibre composites respectively. From the results shown in the figures, we can see that, the contact angles of samples were dramatically decreased initially. Then the contact angles changed very slowly with the elapse of time. After that, the contact angles were approaching to a static value for each of the samples. As compared with the pure epoxy, blends and composites have higher contact angles. With the increase of SAN content, the contact angles at any moment increased in the case of blends.

These results reveal that the addition of the SAN thermoplastic or glass fibre can decrease the hydrophilic nature of the epoxy, and the contact angles can be changed significantly through changing the concentration of the additive. From the above results of contact angles, a general trend of the change of contact angle $(\theta)$ with time $(t)$ for the matrices can be established and schematically 

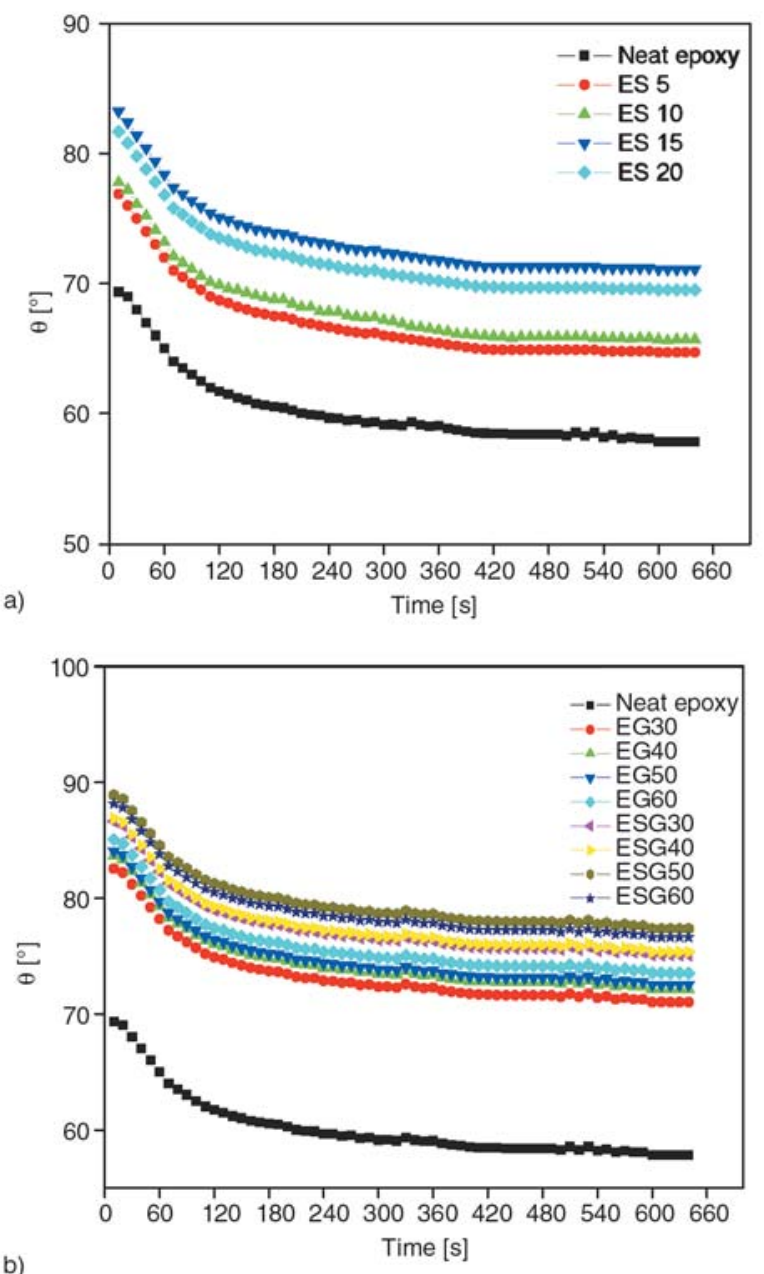

Figure 7. a) Contact angle vs time for epoxy/SAN blends with different concentrations of SAN, b) contact angle vs time for composites with different concentrations of glass fibre

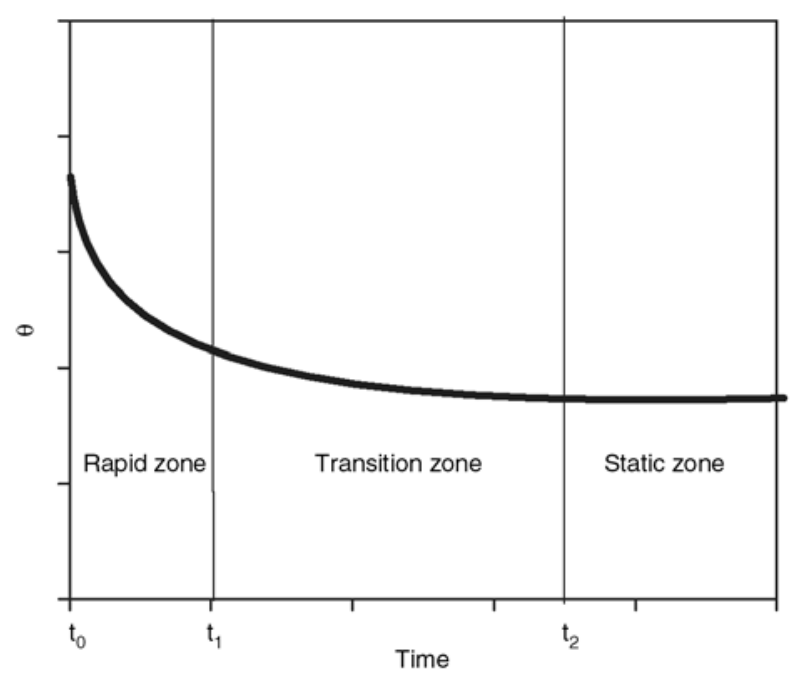

Figure 8. General form of the curves of contact angle $v s$ time shown in Figure 8. From the figure, three characteristic regions on the curves of contact angle with respect to time can be seen. The first region is characterized by a sharp slope in which the contact angle is decreased very rapidly. The second region of the curve shows a much smaller slope, and the third region shows the values of the contact angles are almost constant. The third region on the curve in Figure 8 is characterized by a steady state behavior of wetting. A steady contact angle is reached because the cohesive interaction that helps a drop to form the spherical shape is balanced by the adhesive interaction, which is responsible for the spreading of the liquid [31].

The work of adhesion $\left(W_{A}\right)$, which is the work required to separate the solid and liquid decreases in the case of both blends and composites. This fact is clear from the Figure 9a and Figure 9b, which represents the variation of $W_{A}$ with respect to change in concentration of SAN thermoplastic and glass fibre respectively. The solid surface free
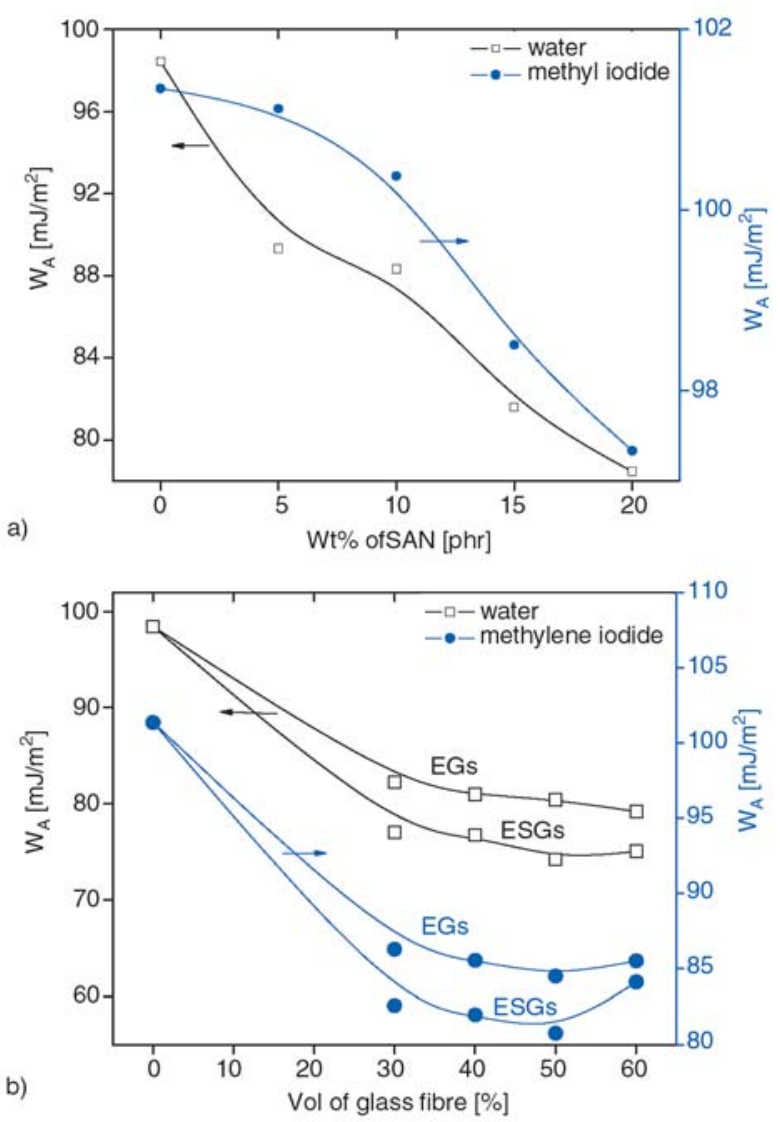

Figure 9. a) Work of adhesion as a function of composition for epoxy/SAN blends with different concentrations of SAN, b) work of adhesion as a function of composition for composites with different concentrations of glass fibre 

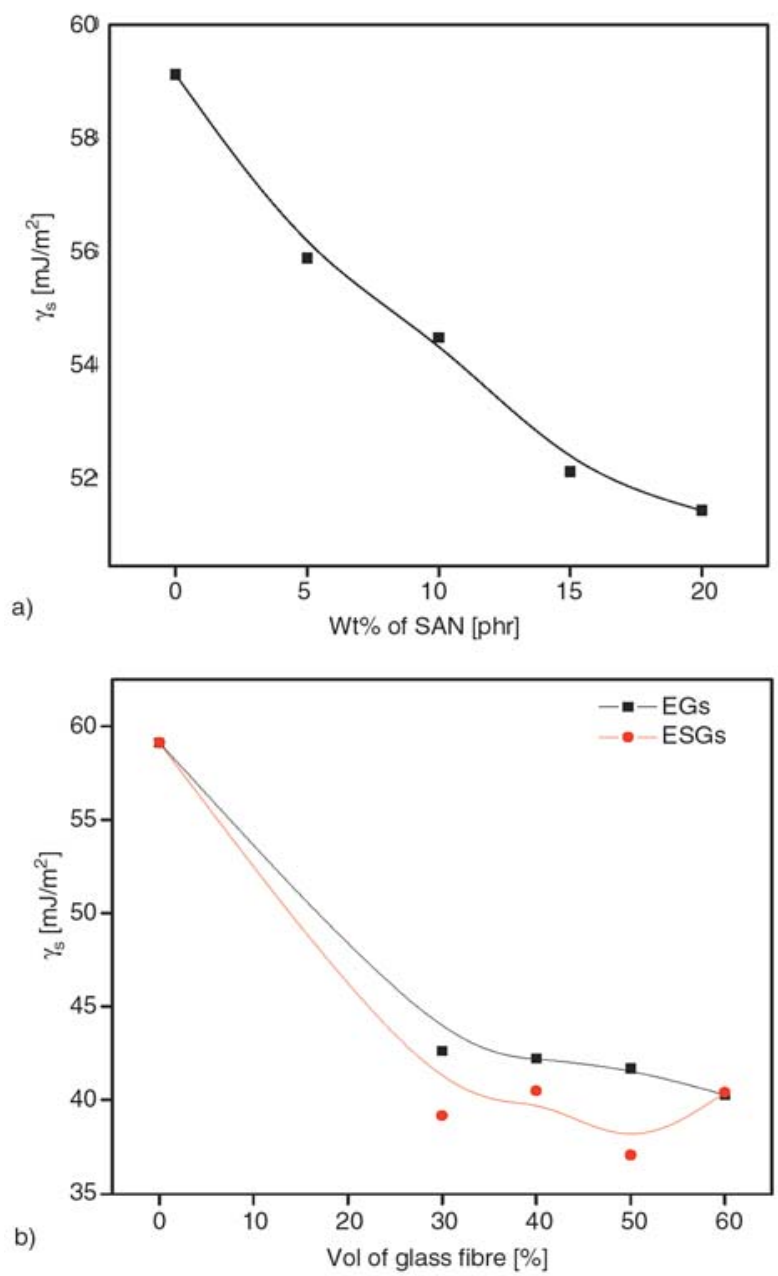

Figure 10. a) Surface free energy as a function of composition for epoxy/SAN blends with different concentrations of SAN, b) surface free energy as a function of composition for composites with different concentrations of glass fibre

Table 4. Surface free energy and Girifalco-Good's interaction parameter of blends and composites

\begin{tabular}{|l|c|c|c|c|c|}
\hline \multicolumn{1}{|c|}{ Sample } & $\gamma_{s}^{d}$ & $\gamma_{s}^{p}$ & $\gamma_{s}$ & $\phi_{w}$ & $\phi_{m}$ \\
\hline Neat epoxy & 47.55 & 11.58 & 59.13 & 0.770 & 0.954 \\
\hline ES5 & 47.15 & 8.71 & 55.87 & 0.701 & 0.939 \\
\hline ES10 & 46.48 & 8.45 & 54.93 & 0.698 & 0.940 \\
\hline ES15 & 44.90 & 6.47 & 51.38 & 0.667 & 0.954 \\
\hline ES20 & 43.11 & 5.67 & 49.58 & 0.654 & 0.950 \\
\hline EG30 & 34.51 & 8.10 & 42.61 & 0.738 & 0.907 \\
\hline EG40 & 34.54 & 7.67 & 42.21 & 0.730 & 0.926 \\
\hline EG50 & 34.07 & 7.60 & 41.67 & 0.730 & 0.925 \\
\hline EG60 & 32.84 & 7.44 & 40.28 & 0.731 & 0.918 \\
\hline ESG30 & 32.26 & 6.89 & 39.15 & 0.721 & 0.923 \\
\hline ESG40 & 34.08 & 6.41 & 40.49 & 0.706 & 0.937 \\
\hline ESG50 & 30.75 & 6.30 & 37.05 & 0.714 & 0.924 \\
\hline ESG60 & 34.59 & 5.81 & 40.41 & 0.691 & 0.945 \\
\hline
\end{tabular}

energy of blends and composites obtained from Equations (2) and (3) based on the contact angle values of water and methylene iodide is plotted in
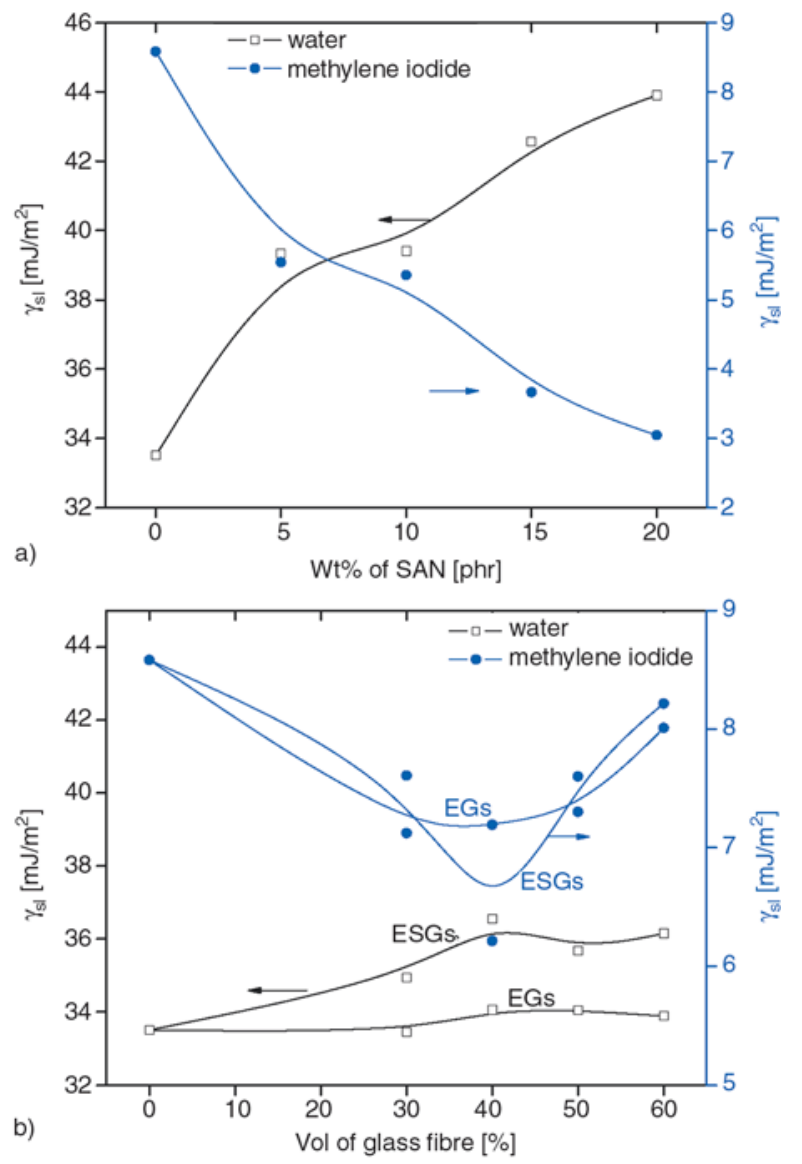

Figure 11. a) Interfacial free energy as a function of composition for epoxy/SAN blends with different concentrations of SAN, b) interfacial free energy as a function of composition for composites with different concentrations of glass fibre

Figures 10a and 10b. It can be seen that the surface free energy decreases with SAN content and the least value was observed in the case of $15 \mathrm{phr}$ blends and 50 vol\% fibre composites. $W_{A}$ and $\gamma_{s}$ are higher and $\theta$ is lower in the case of neat epoxy/ glass fibre composites (EGs) when compared to SAN modified epoxy/glass fibre composites (ESGs).

The surface free energy $\left(\gamma_{s}\right)$ and its dispersive and polar components are given in the Table 4 . It can be observed from the Figure 10a that the $\gamma_{s}$ values showed a decreasing trend upon blending. Both the dispersive as well as the polar components decreased up to $20 \mathrm{phr}$ blends. Whereas, no significant variation in $\gamma_{s}$ can be observed in the case of composites (Figure 10b).

Figures $11 \mathrm{a}$ and $11 \mathrm{~b}$ shows the interfacial free energy $\left(\gamma_{s l}\right)$ between the blend/composite surface and test liquids, water and methylene iodide. Blend surface behaves contradictory to both liquids. $\gamma_{s l}$ of 

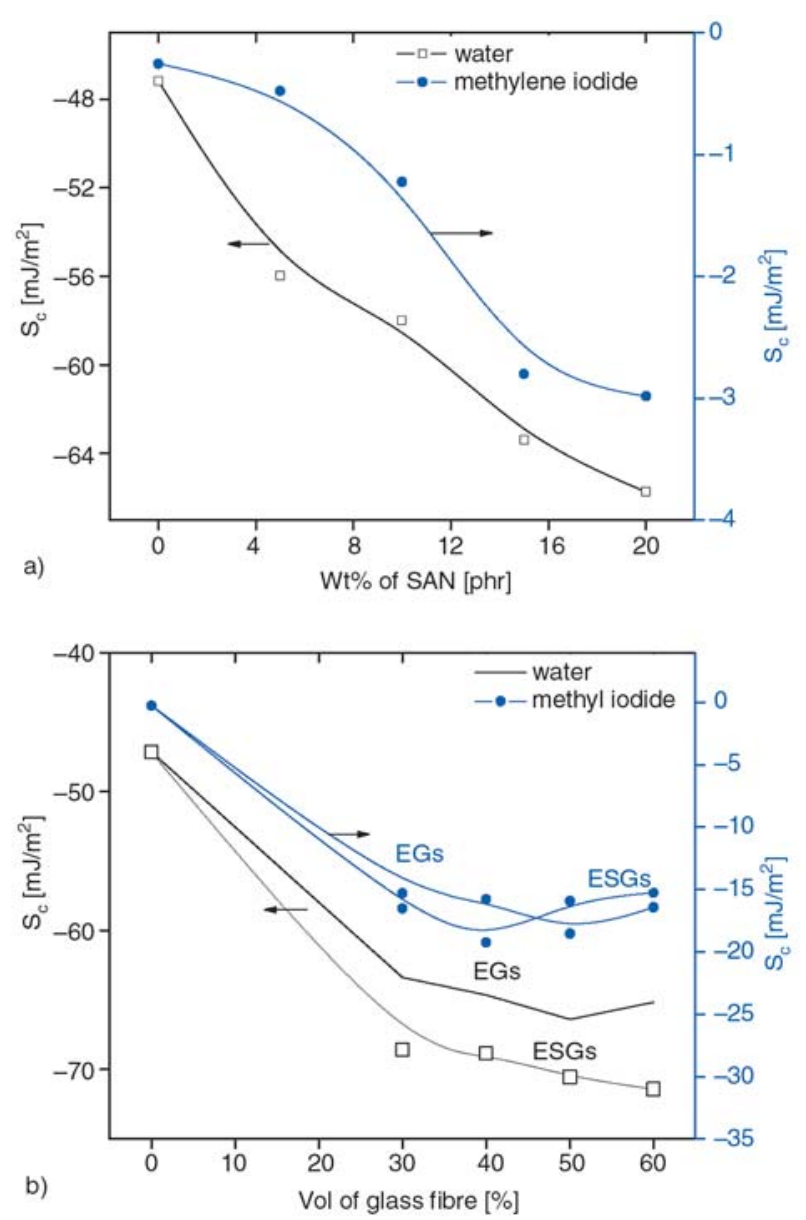

Figure 12. a) Spreading coefficient as a function of composition for epoxy/SAN blends with different concentrations of SAN, b) spreading coefficient as a function of composition for composites with different concentrations of glass fibre

water increase significantly and that of methylene iodide decreases upon blending (Figure 11a). Both these values reach optimum in the case of $20 \mathrm{phr}$ blend. Composites also showed a decreasing trend with respect to fibre loading (Figure 11b).

The spreading coefficient $\left(S_{c}\right)$ implies that a liquid will spontaneously wet and spread on the solid surface if the value is positive. Whereas, a negative value of $S_{c}$ implies the lack of spontaneous wetting and spreading and so the existence of a finite contact angle (i. e., $\theta>0$ ). The spreading coefficients of blends and composites for water and methylene iodide are given in Figure 12. It is to be noted that the wetting due to methylene iodide and water decreases upon blending. The values indicate that methylene iodide (less negative) is the better wetting agent when compared to water for epoxy blends and composites.
Girifalco-Good's interaction parameter $(\phi)$ calculated using Equation (8) provides a good understanding of the degree of interaction between the test liquids and polymer surface. The values are given in the Table 4. A higher value indicates greater interaction. $\phi_{w}$ and $\phi_{m}$ are the GirifalcoGood's interaction parameter due to water and methylene iodide respectively. Highest value was observed in the case of neat epoxy and which decreased upon blending and fibre reinforcing. The interaction of methylene iodide with the polymer surface is higher than that of water. Incorporation of SAN as well as glass fibre reduces $\phi_{w}$ values. From the Girifalco-Good's interaction parameter values it can be suggested that the interaction of a polar liquid like water is reduced and that of a nonpolar liquid like methylene iodide was not changed significantly upon blending.

The polar component of surface free energy $\left(\gamma_{s}^{p}\right)$ decreases as the concentration of SAN increases. This may due to the presence of excess of non-polar groups on the surface of the blends. This nature of the blends also decreases the hydrophilic nature of the blends and composites. The prominent changes in the surface properties such as $W_{A}, \gamma_{s l}, S_{c}$ and $\phi$ with composition of blends and composites are due to the above reasons and also due to the increase in the surface roughness.

\section{Conclusions}

The morphology and wetting behaviour of epoxy/ SAN blends and glass fibre reinforced composites were studied in detail. It was observed that morphology of the blends changed from dispersed, cocontinuous and phase inverted structures as the SAN concentration increased from 5 to $20 \mathrm{phr}$. The roughness of the surface also increased with SAN content. Composites also had a well-packed structure as the glass fibres are closely packed in the matrix. The wetting behaviour showed significant changes in the case of blends and composites. The hydrophobic nature of the blends and composites are well understood from the increase in contact angle value compared to neat resin. The reason was assumed to be the excess number of non-polar groups on the surface and the increase in the roughness of the surface. In general, the effect of thermoplastic and fibre in epoxy is that it reduces the wettability and hydrophilicity of blends and composites. 


\section{References}

[1] Potter W. G.: Epoxide resins. Springer-Verlag, New York (1970).

[2] Tercjak A., Serrano E., Remiro P. M., Mondragon I.: Viscoelastic behavior of thermosetting epoxy mixtures modified with syndiotactic polystyrene during network formation. Journal of Applied Polymer Science, 100, 2348-2355 (2006).

[3] Salmon N., Carlier V., Schut J., Remiro P. M., Mondragon I.: Curing behaviour of syndiotactic polystyrene-epoxy blends: 1 . Kinetics of curing and phase separation process. Polymer International, 54, 667672 (2005).

[4] Francis B., Rao V. L., Ramaswamy R., Jose S., Thomas S., Raju K. V. S. N.: Morphology, viscoelastic properties, and mechanical behavior of epoxy resin modified with hydroxyl-terminated poly(ether ether ketone) oligomer with pendent tert-butyl groups. Polymer Engineering and Science, 45, 1645-1654 (2005).

[5] Blanco I., Cicala G., Lo Faro C.., Recca A.: Development of a toughened DGEBS/DDS system toward improved thermal and mechanical properties by the addition of a tetrafunctional epoxy resin and a novel thermoplastic. Journal of Applied Polymer Science, 89, 268-273 (2003).

[6] Prolongo S. G., Cabanelas J. C., Fine T., Pascault J-P.: Poly(phenylene ether)/epoxy thermoset blends based on anionic polymerization of epoxy monomer. Journal of Applied Polymer Science, 93, 2678-2687 (2004).

[7] Swier S., van Mele B.: The heat capacity signal from modulated temperature DSC in non-isothermal conditions as a tool to obtain morphological information during reaction-induced phase separation. Polymer, 44, 6789-6806 (2003).

[8] Guo Z. S., Du S., Zhang B., Temperature field of thick thermoset composite laminates during cure process. Composites Science and Technology, 65, 517-523 (2005).

[9] Boyard N., Serré C., Vayer M.: A physical approach to define a class A surface in polymer thermosetting composite materials. Journal of Applied Polymer Science, 103, 451-461(2007).

[10] Jacob G. C., Starbuck J. M., Fellers J. F., Simunovic S., Boeman R G.: Fracture toughness in randomchopped fiber-reinforced composites and their strain rate dependence. Journal of Applied Polymer Science, 100, 695-701 (2006).

[11] Mannan K. M., Talukder M. A. I.: Characterization of raw, delignified and bleached jute fibres by study of absorption of moisture and some mechanical properties. Polymer, 38, 2493-2500 (1997).

[12] Cantero G., Arbelaiz A., Llano-Ponte R., Mondragon I.: Effects of fibre treatment on wettability and mechanical behaviour of flax/polypropylene composites. Composites Science and Technology, 63, 12471254 (2003).
[13] Güleç H. A., Sarioglu K., Mutlu M.: Modification of food contacting surfaces by plasma polymerisation technique. Part I: Determination of hydrophilicity, hydrophobicity and surface free energy by contact angle method. Journal of Food Engineering, 75, 187 195 (2006).

[14] Neumann A. W., Good R. J., Hope C. J., Sejpal M.: An equation-of-state approach to determine surface tensions of low-energy solids from contact angles. Journal of Colloid and Interface Science, 49, 291-304 (1974).

[15] Spelt J. K., Li D., Neumann A.W.: The equation of state approach to interracial tensions, in 'Modern Approaches to Wettability' (Eds.: Schrader M. E., Loeb G. I.), Plenum Press, New York, 101 (1992).

[16] Grundke K., Bogumil T., Werner C., Janke A., Pöschel K., Jacobasch H. J.: Liquid-fluid contact angle measurements on hydrophilic cellulosic materials. Colloids and Surfaces A: Physicochemical and Engineering Aspects, 116, 79-91 (1996).

[17] Oss C. J. V., Chaudhury M. K., Good R. J.: Interfacial Lifshitz-van der Waals and polar interactions in macroscopic systems. Chemical Reviews, 88, $927-$ 941 (1988).

[18] Fox H. W., Zisman W. A.: The spreading of liquids on low-energy surfaces. III. Hydrocarbon surfaces. Journal of Colloid Science, 7, 428-442 (1952).

[19] Fowkes F. M.: Additivity of intermolecular forces at interfaces. I. Determination of the contribution to surface and interfacial tensions of dispersion forces in various liquids. Journal of Physical Chemistry, 67, 2538-2541 (1963).

[20] Owens D. K., Wendt R. C.: Estimation of the surface free energy of polymers. Journal of Applied Polymer Science, 13, 1741-1747 (1969).

[21] Kaelble D. H., Dynes P. J., Cirlin E. H.: Interfacial bonding and environmental stability of polymer matrix composites. The Journal of Adhesion, 6, 23-48 (1974).

[22] Wu S.: Calculation of interfacial tension in polymer systems. Journal of Polymer Science Part C: Polymer Symposia, 34, 19-30 (1971).

[23] El-Shimi A., Goddard E. D.: Wettability of some low energy surfaces. Journal of Colloid and Interface Science, 48, 242-248 (1974).

[24] Pyter R. A., Zografi G., Mukerjee P.: Wetting of solids by surface-active agents: The effects of unequal adsorption to vapor-liquid and solid-liquid interfaces. Journal of Colloid and Interface Science, 89, 144-153 (1982).

[25] Lin J. W. P., Dudek L. P., Majumdar D.: Wetting properties of homopolymers and copolymers of pentafluorostyrene and methylacrylate and homopolymer blends. Journal of Applied Polymer Science, 33, 657667 (1987).

[26] Dupré A.: Theorie mechanique de la chaleur. Gauthier-Villars, Paris (1869). 
[27] Francis B., Thomas S., Asari G. V., Ramaswamy R., Jose S., Rao V. L.: Synthesis of Hydroxyl-terminated poly(ether ether ketone) with pendent tert-butyl groups and its use as a toughener for epoxy resins. Journal of Polymer Science Part B: Polymer Physics, 44, 541-556 (2006).

[28] Song X. Z., Zheng S. X., Huang J., Zhu P. P., Guo Q. P.: Miscibility, morphology and fracture toughness of tetrafunctional epoxy resin/poly (styrene-co-acrylonitrile) blends. Journal of Material Science, 35, 56135619 (2000).
[29] Yamanaka K., Inoue T.: Structure development in epoxy resin modified with poly(ether sulphone). Polymer, 30, 662-667 (1989).

[30] Grundke K., Bogumil T., Gietzelt T., Jacobasch H. J., Kwok D. Y., Neumann A. W.: Wetting measurements on smooth, rough and porous solid surfaces. Progress in Colloid and Polymer Science, 101, 58-63 (1996).

[31] Lazghab M., Saleh K., Pezron I., Guigon P. Komunjer L.: Wettability assessment of finely divided solids. Powder Technology, 157, 79-91 (2005). 